\title{
Home activities and cognitive skills in relation to early literacy and numeracy: testing a multifactorial model in preschoolers
}

\author{
Paola Bonifacci ${ }^{1}$ (D) $\cdot$ Nicole Trambagioli $^{1} \cdot$ Luca Bernabini $^{1} \cdot$ Valentina Tobia $^{2,3}$
}

Received: 13 July 2020 /Revised: 24 November 2020 / Accepted: 1 January 2021/

Published online: 5 June 2021

(C) The Author(s) 2021

\begin{abstract}
The aim of the present study was to test environmental and cognitive variables as possible cross-domain predictors of early literacy and numeracy skills. One hundred forty-eight preschool children (mean age $=64.36$ months \pm 3.33 ) were enrolled in the study. The battery included a home literacy and home numeracy questionnaire, measures and phonological and visuo-spatial working memory, tasks tapping response inhibition, and predictors of literacy (vocabulary, phonological awareness, letter knowledge) and numeracy (magnitude comparison, number knowledge) skills. The structural equation model indicated that verbal working memory and, to a lesser extent, inhibition represented cross-domain predictors, whereas home numeracy activities and visuo-spatial working memory explained additional variance only for early numeracy skills. Implications for parents and educators are discussed.
\end{abstract}

Keywords Literacy $\cdot$ Numeracy $\cdot$ Predictors $\cdot$ Memory $\cdot$ Home environment $\cdot$ Preschoolers

Complex mathematical abilities and mature literacy skills (decoding and reading comprehension) are taught at school, but during preschool years, children already spontaneously and intuitively develop basic calculation skills (Levine et al., 1992) and, as far as literacy is concerned, show language-related skills such as phonemic awareness and letter knowledge (Ehri et al., 2001). Previous studies have been focused on the analysis of the two domains separately, although increasing evidence suggests that (1) literacy and mathematical skills might be highly related constructs, particularly in preschool age (Purpura et al., 2011); (2) domain-general cognitive skills explain shared variance for both literacy and numeracy skills (Espy et al., 2004; Gooch et al., 2014);

Paola Bonifacci

paola.bonifacci@unibo.it

1 Department of Psychology, University of Bologna, Viale Berti Pichat n.5, 40127 Bologna, Italy

2 Faculty of Psychology, University Vita-Salute San Raffaele, Via Olgettina 58, 20132 Milan, Italy

3 Child in Mind Lab, Vita-Salute San Raffaele University, Via Olgettina 58, 20132 Milan, Italy 
and (3) environmental variables such as home literacy and home numeracy activities might constitute important mediators of the development of literacy and numeracy skills (Skwarchuk et al., 2014).

Despite the fact that many studies have investigated relationships between early numeracy and literacy skills and have tested, for each of these domains, home environment influences or the relationship with domain-general skills, there is a paucity of studies that have tried to explain, within a single model, the relationships between these different variables altogether. Since the specific role of each of these factors might be partially related or influenced by the others, it is necessary to develop complex models that consider different patterns of predictors together in order to define the contribution of each of them in accounting for the role of the others. The present study assesses a model that includes environmental and cognitive concurrent predictors of literacy and numeracy skills in preschoolers, with the objective of improving knowledge about how these different domain-specific and domain-general skills and environmental variables predict early literacy and numeracy skills when considered together.

\section{Domain-specific components of early literacy and numeracy skills}

Considering early numberacy skills, previous literature has documented that the main predictors of math skills from preschool to primary school include number knowledge (Göbel et al., 2014) and quantity comparison (Clarke \& Shinn, 2004), together with visual-spatial skills (Lambert \& Spinath, 2018). The approximate number system (ANS) (Dehaene, 1992, 2001; Piazza et al., 2010) is a core mechanism involved in number processing that allows to quickly understand, approximate, and manipulate numerical quantities. Besides this non-verbal component, models of number skill development strongly emphasize the role of linguistic components, such as semantic knowledge of numbers (Cirino, 2011; Colomé et al., 2010; LeFevre et al., 2010a; Purpura et al., 2011; Tobia et al., 2021). The relationship between non-verbal approximate numerical abilities and symbolic number knowledge is controversial; some authors suggest that ANS forms an important conceptual foundation for understanding symbolic number words (Gallistel \& Gelman, 1992, 2000; Wagner \& Johnson, 2011), whereas other studies failed to find a relationship between the two (Huntley-Fenner \& Cannon, 2000).

As far as literacy is concerned, previous studies have outlined how letter knowledge and phonemic awareness represent strong predictors of later decoding skills (Torppa et al., 2006; Caravolas, et al., 2013; see Bellocchi et al., 2017 for Italian), whereas general linguistic skills, such as vocabulary, might act as first precursors of the emergence of early literacy skills (phonological awareness and letter knowledge) but are instead considered a direct longitudinal predictor of later reading comprehension skills (Foorman et al., 2015; Hulme et al., 2015).

In summary, numeracy and literacy skills have been proven to have domain-specific predictors (respectively: ANS skills and number knowledge for numeracy, and phonemic awareness and letter knowledge for literacy). However, literacy and numeracy skills have been found to be highly related in both primary school (Singer \& Strasser, 2017) and preschool children (LeFevre et al., 2010a; Purpura et al., 2011). In addition, early literacy skills in preschool years have been found to be related to later mathematical achievement (Hooper et al., 2010; Moll et al., 2015; Romano et al., 2010). Therefore, evidence of literacy and numeracy interrelations opens the way to more complex reflections regarding the possible role of domain-general skills. 


\section{Cognitive predictors of early literacy and numeracy skills}

In a meta-analysis by Singer \& Strasser (2017), the authors outlined a number of different highlevel skills that might explain the relationship between reading and math skills, such as language comprehension, inferences, and metacognition (Cain et al., 2004). Further, they identified putative common underlying cognitive skills, with particular reference to phonological processing and processing speed. The authors actually found that reading and math skills were less related in transparent compared to opaque languages and that they were more related in timed vs. untimed reading and math tasks. Evidence of literacy and numeracy interrelations opens the way to more complex reflections regarding the possible role of domain-general skills, with particular attention to the role of executive functions (EFs) as suggested by previous studies, that found relationships between EFs and academic achievement (Best et al., 2011; Chiappe \& MacDonald, 2005), as well as with literacy (Cummine et al., 2018; Daucourt et al., 2018), numeracy (Mazzocco \& Kover, 2007), or both (e.g., Davidse et al., 2014).

EFs refer to "a family of top-down mental processes needed when you have to concentrate and pay attention" (Diamond, 2013). As suggested by Cragg \& Gilmore (2014), inhibition, working memory, and, to a lesser extent, switching are the three main EFs studied in developmental literature, with a particular focus on the relationship between early literacy and numeracy. The authors also evidenced the need of including EFs within models of numerical development. In the present study, we considered these indications, and we focused on the two processes considered as central by Cragg \& Gilmore (2014), namely, inhibition and working memory.

Inhibition has been defined as the ability to ignore irrelevant information while pursuing a specific goal and being able to control one's attention to override a strong internal or external drive in order to do what is more appropriate (Carlson \& Moses, 2001). Many studies have focused on the analysis of response inhibition skills in preschoolers, because these skills develop rapidly in early childhood (Carlson, 2005), and inhibition tasks are considered a highly familiar task for children of this age, who, in fact, in the preschool setting, are often requested to "inhibit" a prominent response (e.g., not to move/hit/shout, etc.) (Isquith et al., 2004). Furthermore, the ability to inhibit a response has been found to predict school age inhibitory control (Rohrer-Baumgartner et al., 2014; Breaux et al., 2016). For these reasons, response inhibition is the measure considered in the present study, measured through the statue task of the NEPSY, which was found to be a reliable task (Poutanen et al., 2016).

Working memory (WM) can be defined as a mental workspace that is used to manipulate information and that might involve updating and elaboration processing (Engle et al., 1999). Many studies have investigated the role of memory skills as domain-general cognitive predictors of learning-related abilities. In this literature, the two terms, short-term memory and working memory, are both used; short-term memory usually refers to a passive storage, that is, information is deposited and reiterated, and working memory to a more active component that involves manipulation of information. There is however evidence that the distinction between the two constructs is not clear-cut and that there is a large overlap between them (Cowan, 2008; Aben et al., 2012). In the present manuscript, we refer for consistency to the term "Working Memory."

Considering the relationships between EFs and language skills, a study by Slot \& von Suchodoletz (2018) confirmed previous literature that suggested a bidirectional relationship between children's EFs, measured through tasks of inhibition, shifting and working memory, and language skills (vocabulary, grammar). Children with higher language skills at the beginning of preschool showed larger gains in their EFs over the following 10 months. 
Likewise, children who started off with higher EFs exhibited larger gains in their language skills in the following period, with language being a stronger predictor of EFs development than vice versa. Gooch et al. (2014) found that individual differences in language and EFs were strongly related and that weaknesses in EFs and motor skills were associated with language impairment (see also Henry et al., 2012; Im-Bolter et al., 2006; Gooch et al., 2016).

Turning, more specifically, on the relationship between EFs and early literacy skills, findings showed that EF tasks have domain-general predictive power for pre-academic abilities that are less automatic and require more effortful processing of information, such as word writing at preschool age (Schwarz \& Shaul, 2018); in addition, it emerged that inhibition tasks that involve a verbal component are more tightly related to early reading skills compared to nonverbal inhibition tasks (Foy \& Mann, 2013). However, literacy skills might be less related to EFs when considering more automatized skills (e.g., letter knowledge, word recognition) (Blair et al., 2015), but EFs turn out to be meaningful predictors of higher order linguistic skills such as reading comprehension (Nouwens et al., 2020). Phonological WM is highly related to reading skills (Gathercole \& Baddeley, 1993; Wagner \& Torgesen, 1987), although it is an object of debate whether phonological WM has a causal role in literacy development or whether it involves, as reading skills do, access to representations that underlie phonological awareness tasks (Melby-Lervåg et al., 2012). Furthermore, no evidence of a clear relationship between visual-spatial WM and reading prerequisites was found, although it has been suggested that it might have a more substantial role in writing and orthographic skills (Bourke et al., 2014).

Considering numerical development, many studies have found that EFs play a strong role in the early (Schmitt et al., 2017) and late development of math skills (Cragg et al., 2017), as shown, for example, in children as young as 3 years old during quantity comparison tasks with different loads on EFs (Prager et al., 2016). Espy et al. (2004) found that, in preschoolers, WM and response inhibition were related to math ability, but inhibition was the unique predictor after checking for the other EF skills and general intelligence. Purpura et al. (2017) carried out a study on preschoolers in which a wide set of numeracy predictors were tested (including subitizing, cardinality, number knowledge, and story problems); they demonstrated that response inhibition was related to the majority of the mathematical subdomains tested.

For numeracy skills, visual-spatial WM has been documented to be highly related to calculation skills (Tobia et al., 2016), non-symbolic and written arithmetic and word problems (Zhang \& Lin, 2015), counting (Cirino, 2011), and magnitude judgements (Simmons et al., 2012). Although some evidence has suggested that the individual components of WM are related differentially to mathematics (Simmons et al., 2012; Wilson \& Swanson, 2001), other results noted that the whole WM system (rather than a specific memory process) is linked to mathematical knowledge development (Simmons et al., 2008; Zhang et al. 2014). McKenzie et al. (2003) showed that both verbal and visual-spatial WM skills were related to math skills in 8-9-year-old children, while math performance in younger children was mainly affected by visual-spatial skills; the authors suggested that younger and older children make use of different types of WM to solve sums. Further studies have evidenced that weaknesses in phonological WM (Butterworth, 2005) lead to difficulties in storing and remembering arithmetic facts (Koponen et al. 2007; Koponen et al., 2013; Simmons \& Singleton, 2008; Swanson \& Sachse-Lee, 2001; Vanbinst et al., 2015). There is, however, contrasting evidence regarding the predictive role of phonological skills in mathematical development (Passolunghi et al., 2007). Finally, the role of EFs should be considered in relation to the stages of development and 
type of tasks (Cragg \& Gilmore, 2014). There is some evidence that inhibition skills explain more variance in younger children, particularly for procedural learning (Yang et al., 2019), and it has been suggested that the importance of WM for reading decreased with age, whereas the relationship between mathematics and WM increased (Willoughby et al., 2012).

\section{Home literacy and home numeracy}

The role of environmental variables in cognitive development has received progressively increasing attention, also according to theoretical models such as neuroconstructivism (Westermann et al., 2007), that emphasize reciprocal interactions between environmental, genetic, and neurobiological domains. Many studies have addressed the role of home literacy activities in literacy development (Evans et al., 2000; Foy \& Mann, 2003; Hood et al., 2008; Sénéchal \& LeFevre, 2002; Stephenson et al., 2008) and that of home numeracy activities in numerical development (Blevins-Knabe, \& Musun-Miller, 1996; LeFevre et al. 2009; Kleemans et al., 2012; Kleemans et al., 2016; Pan et al., 2006; Bernabini et al., 2020). Most of the literature on home literacy and home numeracy was obtained by means of parents' selfreport questionnaires (Sénéchal \& LeFevre, 2002; LeFevre et al., 2009) suggesting that parents' reports can be considered suitable tools in this research field (Sim et al., 2019).

Currently, in the literature, the nature of the relationship between the home literacy environment and early literacy skills is still under debate. Although researchers agree that an enriched home literacy environment is positively related to early literacy abilities in children, the precise causal patterns, mediators, and functions involved in this pathway are far from clear. A possible limitation of previous studies addressing the direct link between home literacy and children's literacy skills was that a limited number of possible intervening variables that might reduce or hamper the strength of the relationship was considered (Carroll et al., 2019). The present study is aimed at examining relationships between home environment and early literacy and numeracy skills when domain-general children's cognitive skills are also considered.

A relatively minor number of studies have directly investigated the cross-domain effects of home literacy on numeracy and those of home numeracy on literacy. The main issue is to understand whether home learning experiences might have an effect on the development of early literacy and math skills, independently from the specific typology of activity engaged with the children (Melhuish et al. 2008; Skwarchuk et al., 2014), or rather, whether it is necessary to foster specific abilities in the home environment in order to observe specific effects in each domain. For example, Baker (2014) found that the home literacy environment was related to reading but not math prerequisites in Mexican preschool children. In a study by Napoli \& Purpura (2018), it emerged that the home literacy environment was not broadly predictive of children's literacy and numeracy skills, but they found that the home numeracy activities predict a specific aspect of children's literacy development (vocabulary). On the counterpart, some studies have reported that math skills are associated with home literacy experiences at least as strongly as with home numeracy experiences (Anders et al., 2012; LeFevre et al., 2009; LeFevre et al., 2010b). Huntsinger et al. (2016) demonstrated that home numeracy activities predicted both math and reading skills, both concurrently and longitudinally, whereas home literacy activities predicted reading scores concurrently. In a large assessment study, Soto-Calvo \& Sánchez-Barrioluengo (2016) found a strong relation between home literacy tasks and mathematical achievement, with home literacy predicting math scores even after controlling for the effects of early numeracy knowledge. 
Although findings showed mixed results about the cross-domain interactions between home literacy, home numeracy, and children's related skills, they reinforce the importance of assessing the relationship between numerical and literacy development, considering both environmental and individual factors (Anders et al., 2012; Bernabini et al., 2020; Bernabini et al., 2021).

\section{The present study}

The present study was aimed at evaluating concurrent cognitive and environmental predictors of early literacy and numeracy skills in preschool children. More specifically, the novelty of the study is the creation of a model that considers the influence of both environmental and cognitive predictors of early literacy and numeracy skills in preschool children simultaneously. This allows to evaluate common underpinnings and check for cross-domain interactions. Specifically, the study included EF measures of WM skills (phonological and visual-spatial) and response inhibition as domain-general skills; home literacy and home numeracy activities were considered environmental variables. Also, socio-economic status and children's age will be considered control variables. These were included as concurrent predictors of early literacy (vocabulary, phonological awareness, letter knowledge) and numerical skills (quantity comparison, digit knowledge) as dependent latent variables in a group of preschool children. Based on previous literature, we expect from our model to find either domain-specific or crossdomain concurrent predictors of early literacy and numerical skills and to disentangle the differential role of environmental and cognitive factors. More specifically:

1. Among the domain-specific predictors, visual-spatial WM and home numeracy were expected to be the main predictors of early numeracy skills (indexed by quantity comparison and number knowledge) and phonological WM and home literacy to be predictors of early literacy skills (indexed by vocabulary, phonological awareness, and letter knowledge), although a potential minor but significant role of phonological WM for numeracy skills was foreseen (Simmons, \& Singleton, 2008).

2. Among the cross-sectional predictors, response inhibition was expected to be a basic shared predictor of both literacy and numeracy skills, considering the literature supporting both the associations (Cragg \& Gilmore, 2014).

3. For the environmental variables, we expected significant intra-domain associations (i.e., home literacy predicting early literacy and home numeracy predicting early numeracy), but we also hypothesized a possible cross-domain effect of home numeracy on early literacy skills and/or vice versa. The effects of cross-domain interactions of literacy and numeracy activities on children's literacy and math skills should support the idea of the common underpinnings of the two domains.

\section{Method}

\section{Participants}

A total of 148 Italian monolingual children (mean age $=5.36 \pm 0.28$, range $=4.25-6.00$; females $=46.6 \%$ ) attending a public all-day preschool program in Italy took part in this study. None of the children had been referred to neuropsychiatric units for any range of 
developmental disorders or sensory or neurological impairments. The schools, located in a suburban village in northern Italy, were involved in a project aimed at the early identification of literacy and math prerequisites and risk factors. Children were recruited from four schools, with a total of eleven distinct classrooms (range of children in each class: 6-23), that were part of the same school district; the sample was relatively homogeneous for educational exposure, considering, among other aspects, that all the teachers received training on early literacy and math skills within the project. The children were tested at the beginning of the third year of Infancy School, a preschool program that involves children from 3 to 6 years old and does not provide formal instruction in literacy or mathematical skills. All the tasks were administered in Italian.

The parents of all children involved in the study gave their informed consent, and the research ethics committee of the local university approved the project.

\section{Materials}

Background information Information regarding the parents' socio-educational level and occupation were collected and scored, according to the Four Factor Index of Social Status (SES) (Hollingshead, 1975) in order to achieve a composite score for each child's SES. For the present study, indexes of educational level (EL) and occupation (O) were used. A score from 1 to 7 was given for educational level and a score between 1 and 9 for occupation. SES scores for fathers and mothers were then calculated according to the formula $\mathrm{EL} * 3+\mathrm{O} * 5$, and a compound SES score for children was derived from the mean of the two values.

Home literacy and home numeracy questionnaire A short questionnaire assessing home literacy and home numeracy activities (see Appendix, see also Bernabini et al., 2020) was administered to one of the parents, identified as the person who spends more time with the child, usually the mother. We opted for a short questionnaire in order to encourage greater adherence to the study, proposing a questionnaire that is easy to fill out by parents, and in line with other studies that adopted a similar approach (Manolitsis et al., 2013; Stephenson et al., 2008). The questionnaire was composed of 4 questions, which required a response on a fivepoint Likert scale, on home literacy activities (e.g., "How often do you and your child sing nursery rhymes?") and 7 questions on home numeracy activities (e.g., "How often do you and your child count objects aloud?"). Composite scores based on the sum of each subscale were used in the analyses. Reliability for each scale was adequate (Home numeracy: Cronbach's alpha $=.80$; Home literacy: Cronbach's alpha $=.71$ ).

Cognitive assessment A set of different subtests was administered to the children, and these are described in the following paragraphs. All tasks were "child friendly" with animated characters.

Early literacy and language skills The tasks used were taken from the Learning Difficulties Indexes (IDA Battery, Bonifacci et al., 2015). The following tasks were used in the present study:

1. Vocabulary. Children were asked to name 36 images disposed on 3 grids with 12 images each selected for decreasing frequency in spoken language (Burani et al. 2001). The accuracy score, ranging from 0 to 36 ( 1 point for each correct answer), was considered. The Cronbach's alpha of the scale was .85 . 
2. Phonological Awareness. The battery included four different subtests aimed at assessing phonological awareness: syllable blending (6 items), syllable segmentation (6 items), first syllable recognition ( 4 items), and rhymes (4 items). Each item received a score of 1 for correct responses and a score of 0 for incorrect answers, for a maximum total score of 20. The value of Cronbach's alpha was .84 .

3. Letter Knowledge. Children were presented with a picture of a train with one letter (from a to $\mathrm{z}$ ) in each coach. The experimenter had to choose 4 letters within the child's name (familiar letters) and four letters chosen randomly that were not part of the child's name or surname (unfamiliar letters). The child was required to say the sound or the name of the letter indicated by the experimenter. A score of 1 was given for each correct response for a maximum score of 8 . The Cronbach's alpha of the scale was .70 .

Early numeracy skills The tasks used were taken from the battery Number Sense: Prerequisites (SNUP Battery, Tobia et al., 2018). This battery assesses early numeracy skills in preschoolers. To be appealing to such young children, there is a main character, the dragon, who guides children through the tasks. The following tasks were used in the present study:

1. Quantity comparison. Children were shown two illustrated baskets and were asked to quickly choose the one with a greater number of fruits in it, without counting, therefore relying on estimation processes. The number of fruits varied from 3 to 20 , and the difference in quantity between sets varied from 1 to 6 units. A total of 24 items was presented. A score of 1 (correct answer) or 0 (wrong answer) was given for each item, for a maximum total score of 24. There was a Cronbach's alpha of .69.

2. Semantic knowledge of digits. (a) Recognition, (b) reading, and (c) number-quantity association were assessed for digits 1 to 9 . The task was organized as a game, similar to bingo. A card containing the digits 1 to 9 randomly distributed on a grid among blank squares was used for (a) recognition and (b) reading tasks, together with a small bag containing nine number cards, each representing a digit. For the digit (a) recognition task, children indicated on the card the digit picked out of the bag and named aloud by the examiner. In the (b) digit reading task, children were asked to pull out a number from the bag and read it aloud. For the (c) number-quantity association task, children were provided with a card representing sets of elements (baskets of fruit containing from 1 to 9 fruits); the examiner picked and named the nine number cards, requesting the child to choose the set with the corresponding number of fruits. For each digit correctly (a) recognized, (b) read, or (c) associated with a quantity, a score of 1 was given (total score range: 0-27). The Cronbach's alpha of the test was .93.

Working memory To assess working memory, a task on phonological working memory and a task on visual-spatial working memory were selected, from the IDA and the SNUP battery, respectively.

1. Visual-spatial memory. Children were asked to remember the position of one to four items (drawings of the dragon SNUP) on $3 \times 3$ and $4 \times 4$ grids that were presented for 2 and $4 \mathrm{~s}$, respectively, and then covered. Items were presented in an order of increasing difficulty, and a score of 1 was assigned for each item remembered in the correct position. The maximum total score was 26; Cronbach's alpha was .80. 
2. Phonological memory. Children were presented with a non-word repetition task of eight non-words, two 2-syllable, two 3-syllable, two 4-syllable, and two 5-syllable items. Incorrect repetitions were scored 0 . A score of 2 was given for perfectly repeated nonwords, and a score of 1 was assigned when an articulatory error (mispronunciation of the correct sound) was made. The total score ranged from 0 to 16 , and the Cronbach's alpha of the scale was .72 .

Inhibition The Statue subtest from the NEPSY (A Developmental NEuroPSYchological Assessment) battery (Korkman et al., 1998; Italian adaptation: Urgesi \& Fabbro, 2011) was used as a measure of EFs and specifically of response inhibition. The child was required to stand still in a position like a "statue" holding a flag over a 75-s interval while the trained examiner performed four distractor cues: tapping or dropping a pen (after $5 \mathrm{~s}$ ), coughing hard (after $20 \mathrm{~s}$ ), knocking his/her hand twice on the table (after $30 \mathrm{~s}$ ), and clearing his/her throat (after $50 \mathrm{~s}$ ). The number of errors (intentional movements or spoken utterances) was recorded. Visu-Petra et al. (2012) found that the Statue subtest of the NEPSY had the lowest loadings onto a general linguistic factor of the NEPSY battery; this could be equally explained, however, by its simple structure and strong reliance on the earlier maturing function of response inhibition. The test-retest reliability value for children aged 5-6 years old is .79 (Brooks et al., 2009).

\section{Procedure}

All the tasks were administered individually by trained psychologists in a quiet room at the children's school, in a single session lasting about $40 \mathrm{~min}$. The order of tasks was balanced across participants. Breaks were allowed if the child showed signs of fatigue. Special attention was given to ascertaining that children had correctly understood the instructions; verbal instructions were minimized, and examples for each task were provided.

\section{Data analysis}

Pearson correlations between the main variables included in the study were performed. A structural equation model (SEM; e.g., Kline, 2010) including a CFA and a path analysis was applied using MPlus (Muthén \& Muthén, 2010). The CFA identified two latent variables. The first represents early literacy skills and includes vocabulary, phonological awareness, and letter knowledge; the second factor, early math skills, includes the quantity comparison and digit knowledge tasks. A path analysis was used to examine the relationship between these latent dependent variables and the following potential predictors (observed variables): age, SES, home activities in literacy and math as environmental aspects, and verbal and visual-spatial memory, as well as response inhibition, as general cognitive aspects ${ }^{1}$. The maximum likelihood estimation was used, and co-variation between the predictors was considered a default option (Muthén \& Muthén, 2010). The complete model tested is presented in Fig. 1.

\footnotetext{
${ }^{1}$ Gender was also included as a potential predictor in explorative analysis, resulting non-significant. It was not considered in the final tested model.
} 


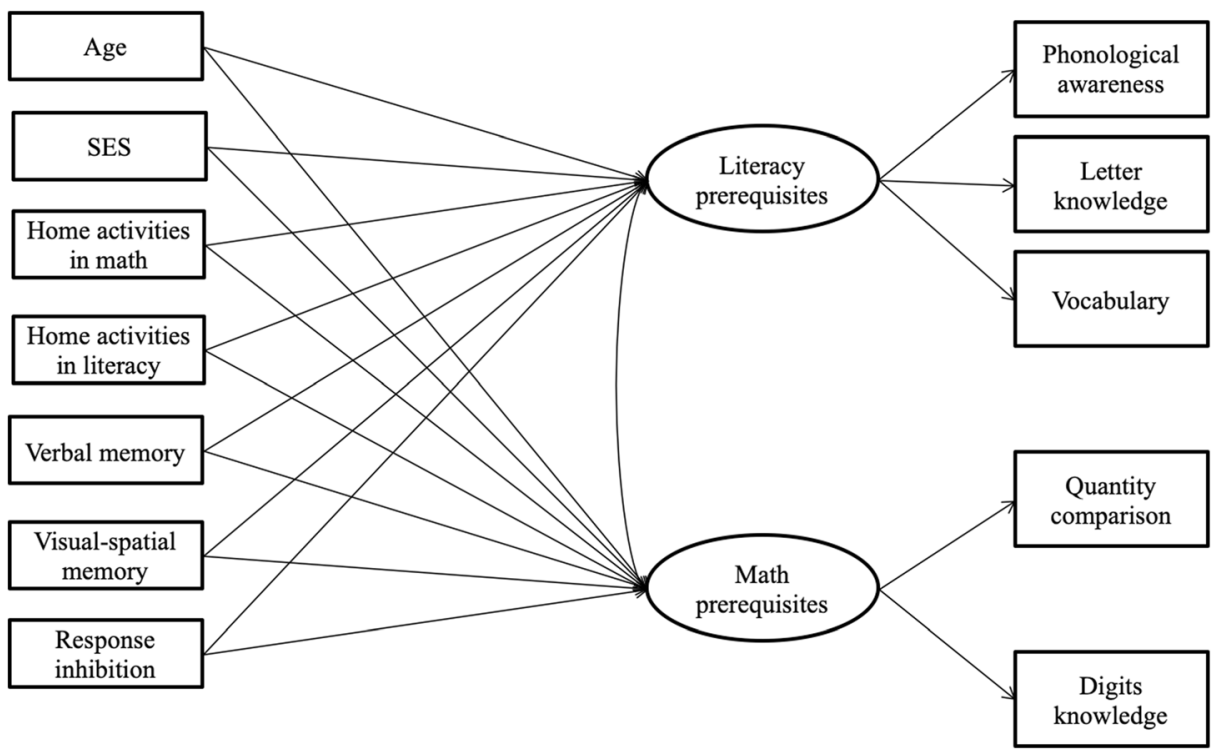

Fig. 1 Model tested with structural equation modeling

Multiple indices were used to evaluate models' fit: chi-square test of model fit $\left(\chi^{2}\right)$, root mean square error of approximation (RMSEA), comparative fit index (CFI), Tucker-Lewis index (TLI), and standardized root mean squared residual (SRMR). A non-significant chisquare test of model fit, TLI, and CFI values equal to or higher than .90 indicate an acceptable model fit; RMSEA and SRMR close to .06 and .08 or lower, respectively, indicate an acceptable fit (Browne \& Cudeck, 1993; Hu \& Bentler, 1999; Marsh et al., 1988).

\section{Results}

Descriptive statistics and correlations among the observed variables are reported in Tables 1 and 2, respectively. As expected, there were significant correlations within domains. Looking at correlations between literacy and numeracy skills, all the subtests were significantly related to each other, although with differing degrees. The highest correlation was found between digits and letter knowledge $(r=.53, p<.01)$ and vocabulary $(r=.43, p<.01)$, while medium correlations were found between phonological awareness and numeracy factors (digit knowledge: $r=.32$; quantity comparison: $r=.36, p<.01$ ) and between vocabulary and quantity comparison $(r=.36, p<.01)$. The lowest, but still significant, correlation was between quantity comparison and letter knowledge $(r=.23, p<.01)$.

Considering correlations among response inhibition, working memory, and literacy and numeracy skills, a complex pattern emerged. Focusing on literacy skills, a significant relationship emerged between phonological awareness and phonological working memory $(r=$ $.36, p<.001)$, which, in turn, was also significantly related to letter knowledge $(r=.20, p<$ $.05)$ and vocabulary $(r=.23, p<.01)$. Significant relationships also emerged between response inhibition and phonological awareness $(r=.24, p<.01)$ and vocabulary $(r=.26, p<.01)$, but not with letter knowledge. Finally, there was a significant relationship between visual-spatial memory and letter knowledge $(r=.22, p<.01)$. 
Table 1 Descriptive statistics for the observed variables

\begin{tabular}{lllll}
\hline & Mean & SD & Range & \% children at floor (score =0) \\
\hline Socio-economic status & 26.91 & 12.52 & $6-53$ & 0 \\
Phonological awareness & 7.20 & 2.76 & $0-10$ & 4.1 \\
Vocabulary & 32.59 & 3.11 & $13-36$ & 0 \\
Letter knowledge & 4.11 & 2.88 & $0-8$ & 12.8 \\
Quantity comparison & 21.72 & 1.87 & $16-24$ & 0 \\
Digits knowledge & 21.58 & 6.03 & $0-27$ & 0.7 \\
Home activities in math & 21.98 & 5.72 & $10-37$ & 0 \\
Home activities in literacy & 12.51 & 3.41 & $4-20$ & 0 \\
Visual-spatial memory & 19.42 & 3.51 & $8-26$ & 0 \\
Verbal memory & 12.99 & 2.23 & $0-16$ & 0.7 \\
Response inhibition & 11.22 & 1.55 & $5-18$ & 0 \\
\hline
\end{tabular}

Turning to the numeracy domain, response inhibition was related to quantity comparison skills $(r=.18, p<.05)$, but not to digit knowledge. Both visual-spatial and phonological working memory were significantly correlated with quantity comparison and digit knowledge ( $r$ ranging from .22 to .28 , all $p s<.01$ ).

Home literacy and home numeracy scales were moderately related to each other $(r=.65, p$ $<.01$ ). Home literacy was related to both tasks of early numeracy (quantity comparison: $r=$ $.23, p<.01$; digit knowledge: $r=.20, p<.05)$ and to letter knowledge $(r=.26, p<.01)$ and vocabulary $(r=.21, p<.05)$, but not to phonological awareness. A similar pattern was observed with home numeracy, related to all tasks ( $r$ ranging from .22 to .28 , all $p s<.01$ ) except phonological awareness. Neither home literacy nor home numeracy were significantly related to SES, working memory, or response inhibition tasks.

To better understand the predictive power of cognitive and environmental variables, these were entered into the structural equation model described in the data analysis. The SEM's fit indices were all acceptable: $\chi^{2}(24)=26.771, p=.315$; RMSEA $=0.028$ (90\% confidence interval 0.000-0.076); $\mathrm{CFI}=0.987$; TLI $=0.975 ; \mathrm{SRMR}=0.033$. The correlation between the unique variances of letter and digit knowledge was allowed, as suggested by MPlus's (Muthén \& Muthén, 2010) modification indices $^{2}$ and supported by past literature on numeral and letter identification in early age (Neumann et al., 2013). Such a minor structural modification is able to improve model fit by increasing the proportion of explained variance, without changing the key conclusions about the adequacy of a hypothesized structure in the description of the data (Bollen, 1989). The design effect was calculated based on the variables' intra-class correlations to check for possible nesting effects due to the involvement of different classrooms; all the values resulted < 2 (Maas \& Hox, 2005; Musca et al., 2011; Muthén \& Satorra, 1995), and the analysis was therefore conducted at the individual level. Figure 2 describes the model fitted to the data and its standardized parameters. The hypothesized paths from the observed variables to the two hypothesized latent variables were all significant.

Early literacy skills were significantly predicted by verbal memory and by response inhibition. The math prerequisite factor was predicted by home activities in math, by both verbal and visual-spatial memory and, marginally $(p=.075)$, by response inhibition. The model explained $40 \%$ and $50 \%$ of variance for literacy and math prerequisites, respectively.

\footnotetext{
${ }^{2}$ Fit indices before the introduction of the correlation between letter and digit knowledge, suggested by the modification indices, were as follows: $\chi^{2}(25)=39.685, p=.031$; RMSEA $=0.064$ (90\% confidence interval $0.020-0.100) ; \mathrm{CFI}=0.929 ; \mathrm{TLI}=0.871 ; \mathrm{SRMR}=0.039$.
} 


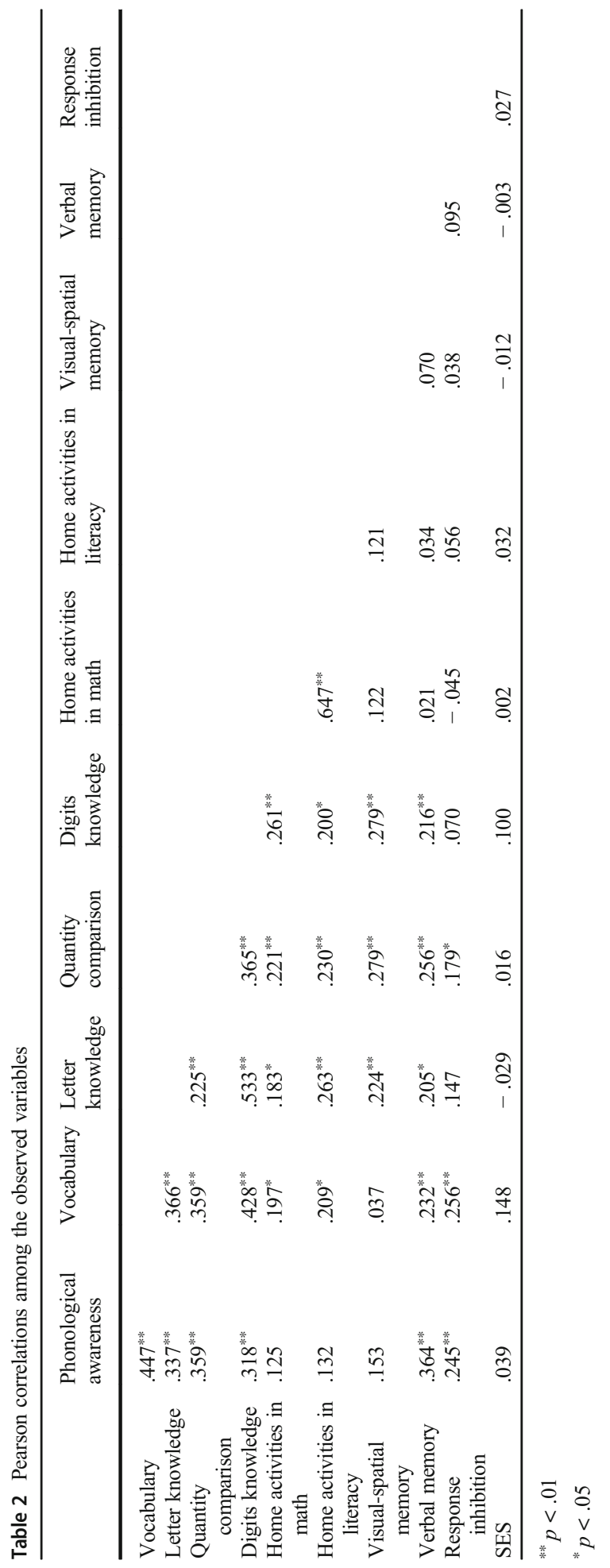




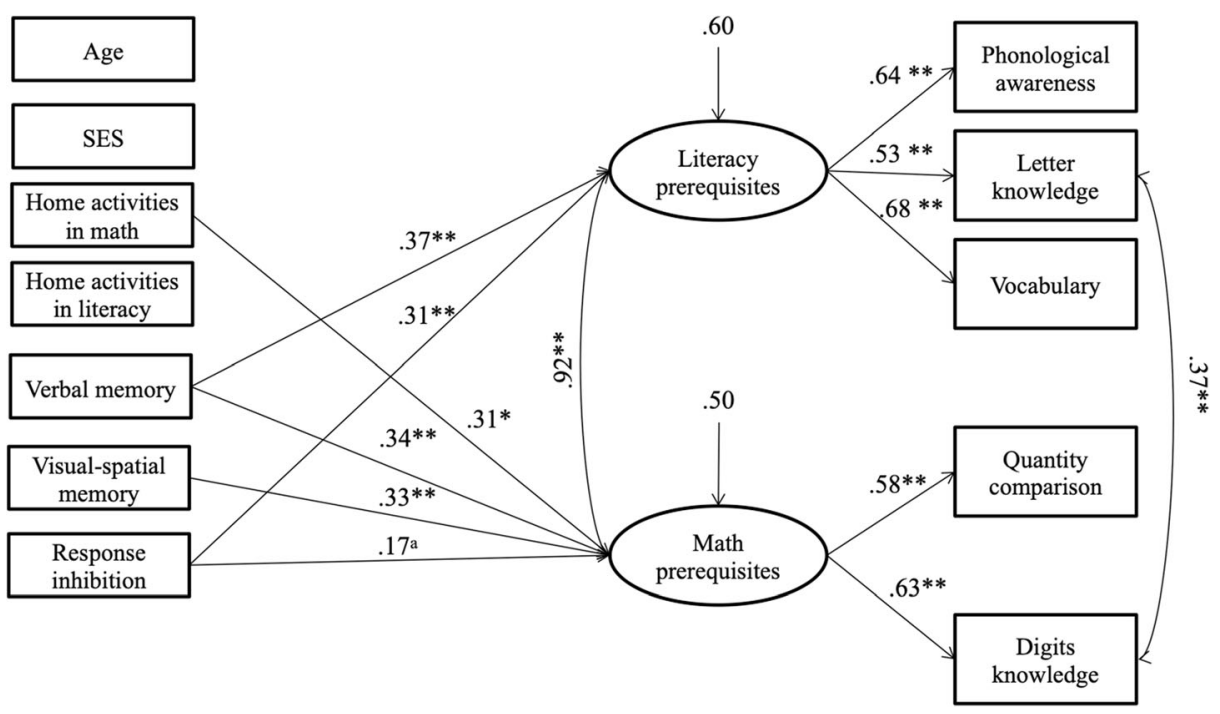

Fig. 2 Standardized model results. Arrows represent significant relationships: $* * p \leq .001 ; * p=.014 ;{ }^{a} p=0.75$. The arrows above the latent variables represent the residual variance for the latent dependent variables

\section{Discussion}

This study was aimed at assessing cognitive and environmental predictors of early literacy and numeracy skills in a group of preschoolers. Specifically, the study aimed to evaluate crossdomain relationships of EFs, measured through response inhibition and working memory, considered as candidates for domain-general predictors of learning prerequisites. Furthermore, home literacy and home numeracy activities were included and collected through questionnaires from parents in order to consider the role of the home environment in early development of literacy and numeracy skills, when considered in interaction with children's cognitive skills. The novelty of the study is, therefore, the creation of a model that considers the influence of both environmental and cognitive predictors of early literacy and numeracy skills in preschool children simultaneously.

Considering the pattern of results obtained from both correlational analyses and the SEM model, a cross-domain interaction emerged between digit and letter knowledge. This pattern of results is consistent with previous literature that demonstrated the interconnection between literacy and numeracy domains (Neumann et al., 2013). In particular, this result emphasizes the connection between verbal label and symbolic representation, which is involved both in letter and number knowledge. Because numbers may be considered "special" letters, it might be hypothesized that both could be considered indexes of symbolic processing or an indirect index of exposure to print (Caravolas et al., 2005).

With reference to the pattern of cognitive predictors, it emerged from the SEM model that response inhibition was a weak $(p=.075)$ concurrent predictor of early numeracy. When looking at simple correlation analyses among subtests, the results showed that response inhibition was significantly related to the quantity comparison task, in line with the study by Prager et al. (2016), but not to digit knowledge. On the counterpart, in the literacy domain, response inhibition was a significant predictor of the early literacy 
factor, and correlations were significant with phonological awareness and vocabulary, but not with letter knowledge. This pattern of results is somewhat different from that observed in the study by Purpura et al. (2017), in which the authors found no correlation between measures of EFs and phonological awareness, in line with Allan \& Lonigan (2011), but found, however, associations with print knowledge. As previously pointed out, letter and number knowledge are thought to rely more on the broader capacity of associating a verbal label with written signs. As suggested by Fuhs \& McNeil (2013) and Gilmore et al. (2013), response inhibition might be a powerful mediator of the relationship between non-symbolic and symbolic processing. Other evidence revealed that, in preschool years, there is a strong concurrent relation between language (including phonological awareness and vocabulary tasks) and inhibition (Slot \& von Suchodoletz, 2018, Gooch et al., 2014). Taken as a whole, these results suggest that inhibition is strongly related to early literacy rather than math skills in preschool age.

The pattern of results regarding WM clearly showed that the visual-spatial component was a significant predictor of early math skills, and the phonological component significantly predicted early literacy skills. This supports previous studies that consistently found a relationship between phonological memory and literacy skills (Baddeley, 2003) and between visual-spatial memory and the numeracy domain (Cirino, 2011). Furthermore, the present results support the idea that phonological processing does indeed have a role in number processing, at least at this developmental stage, an issue on which there are contrasting data in literature; some research did not find a direct relationship (Tobia et al., 2016; Bonifacci et al., 2016), whereas other studies did (Krajewski \& Schneider, 2009).

Finally, considering the role of environmental variables, correlational analyses showed that home literacy and home numeracy scales were significantly related to all numeracy and literacy subtests, except for that testing phonological awareness. However, when variables were considered in the SEM, home numeracy activities were significant predictors of math prerequisites, whereas home literacy had no relationship with either literacy or math prerequisites. This pattern of results confirms previous studies that demonstrated how activities involving numeracy in the home environment represent significant predictors of children's numeracy skills in preschool (Skwarchuk et al., 2014; Bernabini et al., 2020). On the contrary, it emerged that home literacy activities, although related to literacy prerequisites at a correlational level, did not hold a major role in predicting math and literacy skills when included in a more structured model that accounts for variance explained by other variables, such as children's cognitive skills. These data should be considered with caution since they seem to be in contrast with previous findings (e.g., Sénéchal \& LeFevre, 2002) which ascertained a strong link between home literacy environment and children's early literacy development. However, an attempt to explain the present finding might be proposed, based on previous literature and cultural/contextual variable.

First, there are, for example, some contrasting results about the relationship between home literacy and phonological awareness, with some studies that actually found relationships (Foy, \& Mann, 2003; Inoue et al., 2018), whereas others did not (Senechal \& Le Fevre, 2002; Napoli \& Purpura, 2018). Concerning cultural/contextual aspects, it has to be emphasized that the present study was carried out on a population speaking a highly transparent language (i.e., Italian), with high levels of grapheme-phoneme correspondence and with a hypothetical difference in mother-child interaction, compared to other cultures. Some studies have suggested that Italian mothers tend to hold the views that child development is largely a natural process and that adults play only a small role in child growth (New, 1994), but they are more likely to look at and talk to their young 
infants more frequently, as compared to American mothers (Richman et al., 1988), and spend significantly more time in synchronous dyadic social exchanges with their infants (Hsu \& Lavelli, 2005). Girolametto et al. (2002) found that Italian mothers spoke more quickly, used a wider vocabulary, and had more utterances than Canadian mothers. These findings might contribute to suggest a differential role of the home literacy environment in diverse cultural contexts. The hypothesis is that a spontaneously enriched linguistic interaction in Italian mothers might reduce the additional influence of specifically targeted literacy activities. On the contrary, this "verbal" cultural keenness does not seem to be significant in prompting children's numerical skills, which instead benefit from specific teaching and stimulation through numerical-related activities at home.

It emerges that the home numeracy environment, on the other hand, is of specific importance for fostering children's numerical development. This result is in line with past studies investigating the role of home activities regarding numbers in preschoolers' early numeracy skills (e.g., Kleemans et al., 2012) and shows that this link is significant also when considering the role of home literacy, as well as cognitive variables at child level, such as WM.

Within this framework, the absence of relationships between SES and cognitive performance might be, at least in part, connected with cultural and contextual factors. A minor predictive role of SES in Italy has been reported (OECD, 2019), with reported $8.9 \%$ of explained variance in reading, thus minimizing the role of SES in explaining the pattern of strengths and weaknesses in children's performance. Another issue that should be considered is that, in the present study, SES was tested through the evaluation of parents' level of education and employment. However, literature suggest that other more complex measures, which might include income and home resources (number of books, etc.) (Broer et al., 2019), might allow for a more precise measurement of the influence of SES on literacy and numeracy skills.

Another possible limitation of the present study concerns the evaluation of home literacy and home numeracy as unitary constructs. The home literacy model (Sénéchal, 2006; Sénéchal \& LeFevre, 2002; Sénéchal et al., 2017) proposed a distinction between "code-related," formal activities (e.g., teaching letters) and meaning-related, informal activities (e.g., shared book reading); the first are considered predictors of decoding skills and the second of comprehension processes. Considering home literacy as a unique dimension might have led to the loss of information regarding differential effects of specific aspects of exposure (Foy \& Mann, 2003) or to the role of home literacy being underrated as a predictor of early literacy skills. A more in-depth analysis of home literacy, with specific questions about the time spent reading or writing words with children, should be carried out to better disentangle the differential aspects of home literacy domains that might affect literacy development. Furthermore, it has to be underlined that some authors suggested that parents' reports might be affected by social desirability (Sénéchal et al., 1998) and be biased by the abilities and interest of their child (Carroll et al., 2019) or by their own literacy and numeracy skills (Puglisi et al., 2017; van Bergen et al., 2017). Thus, a possible future direction of the present study is the measurement of home literacy/numeracy only through parents' reports together with the use of more objective measures such as direct observation of parent-child interaction and including the assessment of parents' skills. In addition, home activities might not be entirely considered an environmental measure because of a possible gene*environment interaction. However, an important and original contribution of the present paper is to consider children's own domaingeneral cognitive skills, an aspect that has been largely under-investigated in this research area.

Finally, it should be added that the sample was relatively small, and results should be replicated on a larger group of participants, which would make it possible to more 
extensively consider other potentially influencing variables, such as children's gender (Below et al., 2010). Furthermore, this study is cross-sectional, and data collected both concurrently and longitudinally would give more information about the efficacy of the predictors tested. In addition, for each of the domains considered, more tasks should be included, for example, involving more measures of EF skills and measures of active WM, as well as more tasks assessing different domains of literacy and numeracy skills, such as measures that capture elements of children's factual, conceptual, and procedural knowledge (Cragg \& Gilmore, 2014).

Despite these limitations, the results from the present study have shown that literacy and numeracy skills in preschoolers are highly correlated and share some cognitive predictors, with a significant role of EFs, particularly of verbal WM for both literacy and math domains and, to a lesser extent, of inhibition skills. On the other hand, children's abilities in the numeracy domain have specific additional predictors; in particular, they also depend on the visual-spatial WM and home numeracy environment, that is, on the number of activities that parents engage in which are specifically related to number processing. Finally, the home literacy environment, although partially correlated to early literacy and numeracy, did not result as a significant concurrent predictor.

This is one of the first contributions that attempts to model cross-domain predictors of literacy and numeracy prerequisites and that includes both children's cognitive skills and their home environment characteristics. The added value of the present contribution is that children's verbal memory skills and, to a lesser extent, response inhibition are important predictors of their early literacy and numeracy skills and that these variables, together with possible cultural influences, should be considered in future research that assesses the role of home literacy and numeracy in children's development. The present study also represents the first study to assess the relationship between home literacy and numeracy and early literacy and numeracy skills in the Italian context, adding evidence of cross-cultural importance of some domain-general predictors.

The attempt to simultaneously consider cross-domain interactions provides original insight into the related but distinct nature of literacy and numeracy prerequisites, and implications for the educational setting might be proposed. In particular, the fact that numeracy skills had additional variance explained by home environment reinforces the importance of implementing intervention programs aimed at enriching the numeracy domain. Considering the Italian gap in math scores emerging from the PISA program (OECD, 2019), it is important for parents and educators, early on from preschool years, to increase their math talk with children (e.g., naming prices, labels, and measurements of quantities; using quantifiers, etc.), be involved in games involving counting and simple calculation skills, and prompt the child with games where they are required to compare quantities, in order to familiarize children with handling numerals. This study suggests that families should be informed and sensitized about the importance of home environment activities, thus fostering the connection between school and home contexts.

Funding Open access funding provided by Alma Mater Studiorum - Università di Bologna within the CRUICARE Agreement.

Data Availability The data that support the findings of this study are available from the corresponding author upon reasonable request

Code availability Not applicable 


\section{Declarations}

Competing interests The authors declare no competing interests.

\section{Appendix. Questionnaire for parents on home literacy and numeracy activities}

\section{Instructions}

We ask you to think about your child's behavior, and put a cross under "never," "sometimes," "often," "very often," or "everyday," depending on how often you observe the behavior described. How many times does your child do the following activities at home? Rate your responses on the scale detailed below, from 1 (never) to 5 (everyday).

*Items from 1 to 7 refer to home numeracy and items 8 to 11 to home literacy activities.

\begin{tabular}{|c|c|c|c|c|c|c|}
\hline & & Never & Sometimes & Often & $\begin{array}{l}\text { Very } \\
\text { Often }\end{array}$ & $\begin{array}{l}\text { Every } \\
\text { day }\end{array}$ \\
\hline 1 & Count objects & 1 & 2 & 3 & 4 & 5 \\
\hline 2 & Read or write numbers & 1 & 2 & 3 & 4 & 5 \\
\hline 3 & Use games (even on Tablet or PC) that use numbers & 1 & 2 & 3 & 4 & 5 \\
\hline 4 & Use games that use dice & 1 & 2 & 3 & 4 & 5 \\
\hline 5 & Repeat songs that contain numbers & 1 & 2 & 3 & 4 & 5 \\
\hline 6 & $\begin{array}{l}\text { Do activities that require putting objects into order of size } \\
\text { or length }\end{array}$ & 1 & 2 & 3 & 4 & 5 \\
\hline 7 & $\begin{array}{l}\text { Do simple calculations }(2+1=3) \text { in games or during other } \\
\text { daily activities }\end{array}$ & 1 & 2 & 3 & 4 & 5 \\
\hline 8 & Read or write letters of the alphabet & 1 & 2 & 3 & 4 & 5 \\
\hline 9 & Use games (even on Tablet or PC) that use letters & 1 & 2 & 3 & 4 & 5 \\
\hline 10 & Repeat songs that contain rhymes & 1 & 2 & 3 & 4 & 5 \\
\hline 11 & Read or tell stories & 1 & 2 & 3 & 4 & 5 \\
\hline
\end{tabular}

Open Access This article is licensed under a Creative Commons Attribution 4.0 International License, which permits use, sharing, adaptation, distribution and reproduction in any medium or format, as long as you give appropriate credit to the original author(s) and the source, provide a link to the Creative Commons licence, and indicate if changes were made. The images or other third party material in this article are included in the article's Creative Commons licence, unless indicated otherwise in a credit line to the material. If material is not included in the article's Creative Commons licence and your intended use is not permitted by statutory regulation or exceeds the permitted use, you will need to obtain permission directly from the copyright holder. To view a copy of this licence, visit http://creativecommons.org/licenses/by/4.0/.

\section{References}

Aben, B., Stapert, S., \& Blokland, A. (2012). About the distinction between working memory and short-term memory. Frontiers in Psychology, 3, 301.

Allan, N. P., \& Lonigan, C. J. (2011). Examining the dimensionality of effortful control in preschool children and its relation to academic and socioemotional indicators. Developmental Psychology, 47(4), 905-915.

Anders, Y., Rossbach, H. G., Weinert, S., Ebert, S., Kuger, S., Lehrl, S., \& von Maurice, J. (2012). Home and preschool learning environments and their relations to the development of early numeracy skills. Early Childhood Research Quarterly, 27(2), 231-244. 
Baddeley, A. (2003). Working memory and language: An overview. Journal of Communication Disorders, 36(3), 189-208.

Baker, C. E. (2014). Mexican mothers' English proficiency and children's school readiness: Mediation through home literacy involvement. Early Education and Development, 25(3), 338-355.

Bellocchi, S., Tobia, V., \& Bonifacci, P. (2017). Predictors of reading and comprehension abilities in bilingual and monolingual children: A longitudinal study on a transparent language. Reading and Writing, 30(6), 1311-1334.

Below, J. L., Skinner, C. H., Fearrington, J. Y., \& Sorrell, C. A. (2010). Gender differences in early literacy: Analysis of kindergarten through fifth-grade dynamic indicators of basic early literacy skills probes. School Psychology Review, 39(2), 240-257.

van Bergen, E., van Zuijen, T., Bishop, D., \& de Jong, P. F. (2017). Why are home literacy environment and children's reading skills associated? What parental skills reveal. Reading Research Quarterly, 52(2), 147160 .

Bernabini, L., Tobia, V., Guarini, A., \& Bonifacci, P. (2020). Predictors of Children's Early Numeracy: Environmental Variables, Intergenerational Pathways, and Children's Cognitive, Linguistic, and Nonsymbolic Number Skills. Frontiers in Psychology, 11.

Bernabini, L., Tobia, V., \& Bonifacci, P. (2021). Intergenerational Features of Math Skills: Symbolic and NonSymbolic Magnitude Comparison and Written Calculation in Mothers and Children. Journal of Cognition and Development, 22(1), 149-167.

Best, J. R., Miller, P. H., \& Naglieri, J. A. (2011). Relations between executive function and academic achievement from ages 5 to 17 in a large, representative national sample. Learning and Individual Differences, 21(4), 327-336.

Blair, C., Ursache, A., Greenberg, M., \& Vernon-Feagans, L. (2015). Multiple aspects of self-regulation uniquely predict mathematics but not letter-word knowledge in the early elementary grades. Developmental Psychology, 51(4), 459-472.

Blevins-Knabe, B., \& Musun-Miller, L. (1996). Number use at home by children and their parents and its relationship to early mathematical performance. Infant and Child Development, 5(1), 35-45.

Bonifacci, P., Pellizzari, C., Giuliano, P., \& Serra, P. (2015). IDA - Indicatori delle Difficoltà di Apprendimento (Learning Difficulties Index). Florence: Hogrefe editore.

Bonifacci, P., Tobia, V., Bernabini, L., \& Marzocchi, G. M. (2016). Early literacy and numeracy skills in bilingual minority children: Toward a relative independence of linguistic and numerical processing. Frontiers in psychology, 7, 1020.

Bollen, K. A. (1989). Structural equations with latent variables. Wiley.

Bourke, L., Davies, S. J., Sumner, E., \& Green, C. (2014). Individual differences in the development of early writing skills: Testing the unique contribution of visuo-spatial working memory. Reading and Writing, 27(2), 315-335.

Breaux, R. P., Griffith, S. F., \& Harvey, E. A. (2016). Preschool neuropsychological measures as predictors of later attention deficit hyperactivity disorder. Journal of Abnormal Child Psychology, 44(8), 1455-1471.

Broer M., Bai Y., Fonseca F. (2019). A review of the literature on socioeconomic status and educational achievement. In: Socioeconomic inequality and educational outcomes. IEA Research for Education (A Series of In-depth Analyses Based on Data of the International Association for the Evaluation of Educational Achievement (IEA)), vol 5. Springer, Cham.

Brooks, B. L., Sherman, E. M., \& Strauss, E. (2009). NEPSY-II: A developmental neuropsychological assessment. Child Neuropsychology, 16(1), 80-101.

Browne, M. W., \& Cudeck, R. (1993). Alternative ways of assessing model fit. Sage Focus Editions, 154, 136136.

Burani, C., Barca, L., \& Saskia Arduino, L. (2001). Una base di dati sui valori di età di acquisizione, frequenza, familiarità, immaginabilità, concretezza, e altre variabili lessicali e sublessicali per 626 nomi dell'italiano. Giornale Italiano di Psicologia, 28(4), 839-856.

Butterworth, B. (2005). The development of arithmetical abilities. Journal of Child Psychology and Psychiatry, $46(1), 3-18$.

Cain, K., Oakhill, J., \& Bryant, P. (2004). Children's reading comprehension ability: Concurrent prediction by working memory, verbal ability, and component skills. Journal of Educational Psychology, 96(1), 31-42.

Caravolas, M., Kessler, B., Hulme, C., \& Snowling, M. (2005). Effects of orthographic consistency, frequency, and letter knowledge on children's vowel spelling development. Journal of Experimental Child Psychology, 92(4), 307-321.

Caravolas, M., Lervåg, A., Defior, S., Seidlová Málková, G., \& Hulme, C. (2013). Different patterns, but equivalent predictors, of growth in reading in consistent and inconsistent orthographies. Psychological Science, 24(8), 1398-1407. 
Carlson, S. M. (2005). Developmentally sensitive measures of executive function in preschool children. Developmental Neuropsychology, 28(2), 595-616.

Carlson, S. M., \& Moses, L. J. (2001). Individual differences in inhibitory control and children's theory of mind. Child Development, 72(4), 1032-1053.

Carroll, J. M., Holliman, A. J., Weir, F., \& Baroody, A. E. (2019). Literacy interest, home literacy environment and emergent literacy skills in preschoolers. Journal of Research in Reading, 42(1), 150-161.

Chiappe, D., \& MacDonald, K. (2005). The evolution of domain-general mechanisms in intelligence and learning. The Journal of General Psychology, 132(1), 5-40.

Cirino, P. (2011). The interrelationships of mathematical precursors in kindergarten. Journal of Experimental Child Psychology, 108(4), 713-733.

Clarke, B., \& Shinn, M. R. (2004). A preliminary investigation into the identification and development of early mathematics curriculum-based measurement. School Psychology Review, 33(2), 234-248.

Colomé, À., Laka, I., \& Sebastián-Gallés, N. (2010). Language effects in addition: How you say it counts. The Quarterly Journal of Experimental Psychology, 63(5), 965-983.

Cowan, N. (2008). What are the differences between long-term, short-term, and working memory? Progress in Brain Research, 169, 323-338.

Cragg, L., \& Gilmore, C. (2014). Skills underlying mathematics: The role of executive function in the development of mathematics proficiency. Trends in Neuroscience and Education, 3(2), 63-68.

Cragg, L., Keeble, S., Richardson, S., Roome, H., \& Gilmore, C. (2017). Direct and indirect influences of executive functions on mathematics achievement. Cognition, 162, 12-26.

Cummine, J., Aalto, D., Ostevik, A., Cheema, K., \& Hodgetts, W. (2018). "To name or not to name: That is the question": The role of response inhibition in reading. Journal of Psycholinguistic Research, 47(5), 9991014.

Daucourt, M. C., Schatschneider, C., Connor, C. M., Al Otaiba, S., \& Hart, S. A. (2018). Inhibition, updating working memory, and shifting predict reading disability symptoms in a hybrid model: Project KIDS. Frontiers in Psychology, 9, 238.

Davidse, N. J., De Jong, M. T., \& Bus, A. G. (2014). Explaining common variance shared by early numeracy and literacy. Reading and Writing, 27(4), 631-648.

Dehaene, S. (1992). Varieties of numerical abilities. Cognition, 44(1), 1-42.

Dehaene, S. (2001). Précis of the number sense. Mind \& Language, 16(1), 16-36.

Diamond, A. (2013). Executive functions. Annual Review of Psychology, 64(1), 135-168.

Duncan, G. J., Dowsett, C. J., Claessens, A., Magnuson, K., Huston, A. C., Klebanov, P., et al. (2007). School readiness and later achievement. Developmental Psychology, 43(6), 1428-1446.

Ehri, L. C., Nunes, S. R., Willows, D. M., Schuster, B. V., Yaghoub-Zadeh, Z., \& Shanahan, T. (2001). Phonemic awareness instruction helps children learn to read: Evidence from the National Reading Panel's meta-analysis. Reading Research Quarterly, 36(3), 250-287.

Engle, R. W., Tuholski, S. W., Laughlin, J. E., \& Conway, A. R. (1999). Working memory, short-term memory, and general fluid intelligence: A latent-variable approach. Journal of Experimental Psychology: General, 128(3), 309-331.

Espy, K. A., McDiarmid, M. M., Cwik, M. F., Stalets, M. M., Hamby, A., \& Senn, T. E. (2004). The contribution of executive functions to emergent mathematic skills in preschool children. Developmental Neuropsychology, 26(1), 465-486.

Evans, M. A., Shaw, D., \& Bell, M. (2000). Home literacy activities and their influence on early literacy skills. Canadian Journal of Experimental Psychology/Revue canadienne de psychologie expérimentale, 54(2), 6575.

Foorman, B. R., Herrera, S., Petscher, Y., Mitchell, A., \& Truckenmiller, A. (2015). The structure of oral language and reading and their relation to comprehension in Kindergarten through Grade 2. Reading and Writing, 28(5), 655-681.

Foy, J., \& Mann, V. (2003). Home literacy environment and phonological awareness in preschool children: Differential effects for rhyme and phoneme awareness. Applied PsychoLinguistics, 24(1), 59-88.

Foy, J. G., \& Mann, V. A. (2013). Executive function and early reading skills. Reading and Writing, 26(3), 453-472.

Fuhs, M. W., \& McNeil, N. M. (2013). ANS acuity and mathematics ability in preschoolers from low-income homes: Contributions of inhibitory control. Developmental Science, 16(1), 136-148.

Gallistel, C. R., \& Gelman, R. (1992). Preverbal and verbal counting and computation. Cognition, 44(1-2), 4374.

Gallistel, C. R., \& Gelman, R. (2000). Non-verbal numerical cognition: From reals to integers. Trends in Cognitive Sciences, 4(2), 59-65.

Gathercole, S. E., \& Baddeley, A. D. (1993). Phonological working memory: A critical building block for reading development and vocabulary acquisition? European Journal of Psychology of Education, 8(3), 259272 . 
Gilmore, C., Attridge, N., Clayton, S., Cragg, L., Johnson, S., Marlow, N., Simms, V., \& Inglis, M. (2013). Individual differences in inhibitory control, not non-verbal number acuity, correlate with mathematics achievement. PLoS One, 8(6), e67374.

Girolametto, L., Bonifacio, S., Visini, C., Weitzman, E., Zocconi, E., \& Pearce, P. (2002). Mother-child interactions in Canada and Italy: Linguistic responsiveness to late-talking toddlers. International Journal of Language \& Communication Disorders, 37(2), 153-171.

Göbel, S. M., Watson, S. E., Lervåg, A., \& Hulme, C. (2014). Children's arithmetic development: It is number knowledge, not the approximate number sense, that counts. Psychological Science, 25(3), 789-798.

Gooch, D., Hulme, C., Nash, H., \& Snowling, M. (2014). Comorbidities in preschool children at family risk of dyslexia. Journal of Child Psychology and Psychiatry, 55(3), 237-246.

Gooch, D., Thompson, P., Nash, H., Snowling, M., \& Hulme, C. (2016). The development of executive function and language skills in the early school years. Journal of Child Psychology and Psychiatry, 57(2), 180-187.

Henry, L. A., Messer, D. J., \& Nash, G. (2012). Executive functioning in children with specific language impairment. Journal of Child Psychology and Psychiatry, 53(1), 37-45.

Hollingshead, A. B. (1975). Four factor index of social status1. Yale Journal Of Sociology, 21.

Hood, M., Conlon, E., \& Andrews, G. (2008). Preschool home literacy practices and children's literacy development: A longitudinal analysis. Journal of Educational Psychology, 100(2), 252-271.

Hooper, S. R., Roberts, J., Sideris, J., Burchinal, M., \& Zeisel, S. (2010). Longitudinal predictors of reading and math trajectories through middle school for African American versus Caucasian students across two samples. Developmental Psychology, 46(5), 1018-1029.

Hsu, H. C., \& Lavelli, M. (2005). Perceived and observed parenting behavior in American and Italian first-time mothers across the first 3 months. Infant Behavior and Development, 28(4), 503-518.

Hu, L. T., \& Bentler, P. M. (1999). Cutoff criteria for fit indexes in covariance structure analysis: Conventional criteria versus new alternatives. Structural Equation Modeling: A Multidisciplinary Journal, 6(1), 1-55.

Hulme, C., Nash, H. M., Gooch, D., Lervåg, A., \& Snowling, M. J. (2015). The foundations of literacy development in children at familial risk of dyslexia. Psychological Science, 26(12), 1877-1886.

Huntley-Fenner, G., \& Cannon, E. (2000). Preschoolers' magnitude comparisons are mediated by a preverbal analog mechanism. Psychological Science, 11(2), 147-152.

Huntsinger, C. S., Jose, P. E., \& Luo, Z. (2016). Parental facilitation of early mathematics and reading skills and knowledge through encouragement of home-based activities. Early Childhood Research Quarterly, 37, 115.

Im-Bolter, N., Johnson, J., \& Pascual-Leone, J. (2006). Processing limitations in children with specific language impairment: The role of executive function. Child Development, 77(6), 1822-1841.

Inoue, T., Georgiou, G. K., Parrila, R., \& Kirby, J. R. (2018). Examining an extended home literacy model: The mediating roles of emergent literacy skills and reading fluency. Scientific Studies of Reading, 22(4), 273288.

Isquith, P. K., Gioia, G. A., \& Espy, K. A. (2004). Executive function in preschool children: Examination through everyday behavior. Developmental Neuropsychology, 26(1), 403-422.

Kleemans, T., Peeters, M., Segers, E., \& Verhoeven, L. (2012). Child and home predictors of early numeracy skills in kindergarten. Early Childhood Research Quarterly, 27(3), 471-477.

Kleemans, T., Segers, E., \& Verhoeven, L. (2016). Relations between home numeracy experiences and basic calculation skills of children with and without specific language impairment. Early Childhood Research Quarterly, 28(2), 415-423.

Kline, R. B. (2010). Principles and practice of structural equation modeling (3rd ed.). Guilford Press.

Koponen, T., Aunola, K., Ahonen, T., \& Nurmi, J.-E. (2007). Cognitive predictors of single-digit and procedural calculation skills and their covariation with reading skill. Journal of Experimental Child Psychology, 97(3), 220-241.

Koponen, T., Salmi, P., Eklund, K., \& Aro, T. (2013). Counting and RAN: Predictors of arithmetic calculation and reading fluency. Journal of Educational Psychology, 105(1), 162-175.

Korkman, M., Kirk, U., \& Kemp, S. (1998). NEPSY: A developmental neuropsychological assessment. Psychological Corporation.

Krajewski, K., \& Schneider, W. (2009). Exploring the impact of phonological awareness, visual-spatial working memory, and preschool quantity-number competencies on mathematics achievement in elementary school: Findings from a 3-year longitudinal study. Journal of Experimental Child Psychology, 103(4), 516-531.

Lambert, K., \& Spinath, B. (2018). Conservation abilities, visuospatial skills, and numerosity processing speed: Association with math achievement and math difficulties in elementary school children. Journal of Learning Disabilities, 51(3), 223-235.

LeFevre, J. A., Skwarchuk, S. L., Smith-Chant, B. L., Fast, L., Kamawar, D., \& Bisanz, J. (2009). Home numeracy experiences and children's math performance in the early school years. Canadian Journal of Behavioural Science/Revue canadienne des sciences du comportement, 41(2), 55-66. 
LeFevre, J. A., Fast, L., Skwarchuk, S. L., Smith-Chant, B. L., Bisanz, J., Kamawar, D., \& Penner-Wilger, M. (2010a). Pathways to mathematics: Longitudinal predictors of performance. Child Development, 81(6), 1753-1767.

LeFevre, J. A., Polyzoi, E., Skwarchuk, S. L., Fast, L., \& Sowinski, C. (2010b). Do home numeracy and literacy practices of Greek and Canadian parents predict the numeracy skills of kindergarten children? International Journal of Early Years Education, 18(1), 55-70.

Levine, S. C., Jordan, N. C., \& Huttenlocher, J. (1992). Development of calculation abilities in young children. Journal of Experimental Child Psychology, 53(1), 72-103.

Maas, C. J., \& Hox, J. J. (2005). Sufficient sample sizes for multilevel modeling. Methodology, 1(3), 86-92.

Manolitsis, G., Georgiou, G. K., \& Tziraki, N. (2013). Examining the effects of home literacy and numeracy environment on early reading and math acquisition. Early Childhood Research Quarterly, 28(4), 692-703.

Marsh, H. W., Balla, J. R., \& McDonald, R. P. (1988). Goodness-of-fit indexes in confirmatory factor analysis: The effect of sample size. Psychological Bulletin, 103(3), 391-410.

Mazzocco, M. M., \& Kover, S. T. (2007). A longitudinal assessment of executive function skills and their association with math performance. Child Neuropsychology, 13(1), 18-45.

McKenzie, B., Bull, R., \& Gray, C. (2003). The effects of phonological and visual-spatial interference on childrens' arithmetical performance. Educational and Child Psychology, 20(3), 93-108.

Melby-Lervåg, M., Lyster, S. A. H., \& Hulme, C. (2012). Phonological skills and their role in learning to read: A meta-analytic review. Psychological Bulletin, 138(2), 322-352.

Melhuish, E. C., Phan, M. B., Sylva, K., Sammons, P., Siraj-Blatchford, I., \& Taggart, B. (2008). Effects of the home learning environment and preschool center experience upon literacy and numeracy development in early primary school. Journal of Social Issues, 64(1), 95-114.

Moll, K., Snowling, M., Göbel, S., \& Hulme, C. (2015). Early language and executive skills predict variations in number and arithmetic skills in children at family-risk of dyslexia and typically developing controls. Learning and Instruction, 38, 53-62.

Musca, S. C., Kamiejski, R., Nugier, A., Méot, A., Er-Rafiy, A., \& Brauer, M. (2011). Data with hierarchical structure: Impact of intraclass correlation and sample size on Type-I error. Frontiers in Psychology, 2, 74.

Muthén, L. K., \& Muthén, B. O. (2010). Mplus user's guide: Statistical analysis with latent variables: User's Guide. Muthén \& Muthén.

Muthén, B., \& Satorra, A. (1995). Complex sample data in structural equation modeling. In P. V. Marsden (Ed.), Sociological methodology (pp. 267-316). Oxford, England: Blackwell.

Napoli, A. R., \& Purpura, D. J. (2018). The home literacy and numeracy environment in preschool: Crossdomain relations of parent-child practices and child outcomes. Journal of Experimental Child Psychology, $166,581-603$.

Neumann, M. M., Hood, M., Ford, R. M., \& Neumann, D. L. (2013). Letter and numeral identification: their relationship with early literacy and numeracy skills. European Early Childhood Education Research Journal, 21(4), 489-501.

New, R. S. (1994). Child's play—una cosa natural: An Italian perspective. Children's play in diverse cultures, $123-147$.

Nouwens, S., Groen, M. A., Kleemans, T., \& Verhoeven, L. (2020). How executive functions contribute to reading comprehension. British Journal of Educational Psychology, e12355.

OECD. (2019). PISA 2018 Results (Volume II): Where all students can succeed. PISA, OECD Publishing, Paris. https://doi.org/10.1787/b5fd1b8f-en.

Pan, Y., Gauvain, M., Liu, Z., \& Cheng, L. (2006). American and Chinese parental involvement in young children's mathematics learning. Cognitive Development, 21(1), 17-35.

Passolunghi, M. C., Vercelloni, B., \& Schadee, H. (2007). The precursors of mathematics learning: Working memory, phonological ability and numerical competence. Cognitive Development, 22(2), 165-184.

Piazza, M., Facoetti, A., Trussardi, A. N., Berteletti, I., Conte, S., Lucangeli, D., Dehaene, S., \& Zorzi, M. (2010). Developmental trajectory of number acuity reveals a severe impairment in developmental dyscalculia. Cognition, 116(1), 33-41.

Poutanen, M., Berg, S., Kangas, T., Peltomaa, K., Lahti-Nuuttila, P., \& Hokkanen, L. (2016). Before and after entering school: The development of attention and executive functions from 6 to 8 years in Finnish children. Scandinavian Journal of Psychology, 57(1), 1-11.

Prager, E., Sera, M., \& Carlson, S. (2016). Executive function and magnitude skills in preschool children. Journal of Experimental Child Psychology, 147, 126-139.

Puglisi, M. L., Hulme, C., Hamilton, L. G., \& Snowling, M. J. (2017). The home literacy environment is a correlate, but perhaps not a cause, of variations in children's language and literacy development. Scientific Studies of Reading, 21(6), 498-514. 
Purpura, D. J., Hume, L. E., Sims, D. M., \& Lonigan, C. J. (2011). Early literacy and early numeracy: The value of including early literacy skills in the prediction of numeracy development. Journal of Experimental Child Psychology, 110(4), 647-658.

Purpura, D., Schmitt, S., \& Ganley, C. (2017). Foundations of mathematics and literacy: The role of executive functioning components. Journal of Experimental Child Psychology, 153, 15-34.

Richman, A. L., LeVine, R. A., New, R. S., Howrigan, G. A., Welles-Nystrom, B., \& LeVine, S. E. (1988). Maternal behavior to infants in five cultures. New Directions for Child Development, 1988(40), 81-97.

Rohrer-Baumgartner, N., Zeiner, P., Egeland, J., Gustavson, K., Skogan, A. H., Reichborn-Kjennerud, T., \& Aase, H. (2014). Does IQ influence associations between ADHD symptoms and other cognitive functions in young preschoolers? Behavioral and Brain Functions, $10(1), 16$.

Romano, E., Babchishin, L., Pagani, L. S., \& Kohen, D. (2010). School readiness and later achievement: Replication and extension using a nationwide Canadian survey. Developmental Psychology, 46(5), 9951007.

Schmitt, S. A., Geldhof, G. J., Purpura, D. J., Duncan, R., \& McClelland, M. M. (2017). Examining the relations between executive function, math, and literacy during the transition to kindergarten: A multi-analytic approach. Journal of Education \& Psychology, 109(8), 1120-1140. https://doi.org/10.1037/edu0000193.

Schwarz, M., \& Shaul, S. (2018). Towards a better understanding of the link between executive functions, early literacy, and emergent mathematical abilities. Written Language \& Literacy, 21(2), 238-268.

Sénéchal, M. (2006). Testing the home literacy model: Parent involvement in kindergarten is differentially related to grade 4 reading comprehension, fluency, spelling, and reading for pleasure. Scientific Studies of Reading, $10(1), 59-87$.

Sénéchal, M., \& LeFevre, J. A. (2002). Parental involvement in the development of children's reading skill: A five-year longitudinal study. Child Development, 73(2), 445-460.

Sénéchal, M., Lefevre, J. A., Thomas, E. M., \& Daley, K. E. (1998). Differential effects of home literacy experiences on the development of oral and written language. Reading Research Quarterly, 33(1), 96-116.

Sénéchal, M., Whissell, J., \& Bildfell, A. (2017). Starting from home: Home literacy practices that make a difference. Theories of reading development, 15, 383.

Sim, F., Thompson, L., Marryat, L., Ramparsad, N., \& Wilson, P. (2019). Predictive validity of preschool screening tools for language and behavioural difficulties: A PRISMA systematic review. PLoS One, 14(2), e0211409.

Simmons, F. R., \& Singleton, C. (2008). Do weak phonological representations impact on arithmetic development? A review of research into arithmetic and dyslexia. Dyslexia, 14(2), 77-94.

Simmons, F., Singleton, C., \& Horne, J. (2008). Brief report-Phonological awareness and visual-spatial sketchpad functioning predict early arithmetic attainment: Evidence from a longitudinal study. European Journal of Cognitive Psychology, 20(4), 711-722.

Simmons, F. R., Willis, C., \& Adams, A. (2012). Different components of working memory have different relationships with different mathematical skills. Journal of Experimental Child Psychology, 111(2), 139155 .

Singer, V., \& Strasser, K. (2017). The association between arithmetic and reading performance in school: A meta-analytic study. School Psychology Quarterly, 32(4), 435-448. https://doi.org/10. 1037/spq0000197.

Skwarchuk, S. L., Sowinski, C., \& LeFevre, J. A. (2014). Formal and informal home learning activities in relation to children's early numeracy and literacy skills: The development of a home numeracy model. Journal of Experimental Child Psychology, 121, 63-84.

Slot, P. L., \& von Suchodoletz, A. (2018). Bidirectionality in preschool children's executive functions and language skills: Is one developing skill the better predictor of the other? Early Childhood Research Quarterly, 42, 205-214.

Soto-Calvo, E. \& Sánchez-Barrioluengo, M. (2016). The influence of early literacy competences on later mathematical attainment: Evidence from TIMSS \& PIRLS 2011. EUR 28010 EN.

Stephenson, K. A., Parrila, R. K., Georgiou, G. K., \& Kirby, J. R. (2008). Effects of home literacy, parents' beliefs, and children's task-focused behavior on emergent literacy and word reading skills. Scientific Studies of Reading, 12(1), 24-50.

Swanson, H. L., \& Sachse-Lee, C. (2001). Mathematical problem solving and working memory in children with learning disabilities: Both executive and phonological processes are important. Journal of Experimental Child Psychology, 79(3), 294-321.

Tobia, V., Bonifacci, P., \& Marzocchi, G. M. (2021). Symbolic versus non-symbolic training for improving early numeracy in preschoolers at risk of developing difficulties in mathematics. Research in Developmental Disabilities, 111, 103893.

Tobia, V., Bonifacci, P., and Marzocchi, G. M. (2018). SNUP - Senso del Numero: Prerequisiti (Sense of Number: Prerequisites). Florence: Hogrefe editore. 
Tobia, V., Bonifacci, P., \& Marzocchi, G. M. (2016). Concurrent and longitudinal predictors of calculation skills in preschoolers. European journal of psychology of education, 31(2), 155-174.

Torppa, M., Poikkeus, A. M., Laakso, M. L., Eklund, K., \& Lyytinen, H. (2006). Predicting delayed letter knowledge development and its relation to grade 1 reading achievement among children with and without familial risk for dyslexia. Developmental Psychology, 42(6), 1128-1142.

Urgesi, C., \& Fabbro, F. (2011). NEPSY-2: contributo alla taratura italiana. Giunti OS.

Vanbinst, K., Ceulemans, E., Ghesquière, P., \& De Smedt, B. (2015). Profiles of children's arithmetic fact development: A model-based clustering approach. Journal of Experimental Child Psychology, 133, $29-46$.

Visu-Petra, L., Cheie, L., Benga, O., \& Miclea, M. (2012). The structure of executive functions in preschoolers: An investigation using the NEPSY battery. Procedia-Social and Behavioral Sciences, 33, 627-631.

Wagner, J. B., \& Johnson, S. C. (2011). An association between understanding cardinality and analog magnitude representations in preschoolers. Cognition, 119(1), 10-22.

Wagner, R. K., \& Torgesen, J. K. (1987). The nature of phonological processing and its causal role in the acquisition of reading skills. Psychological Bulletin, 101(2), 192-212.

Westermann, G., Mareschal, D., Johnson, M. H., Sirois, S., Spratling, M. W., \& Thomas, M. S. (2007). Neuroconstructivism. Developmental Science, 10(1), 75-83.

Willoughby, M. T., Blair, C. B., Wirth, R. J., \& Greenberg, M. (2012). The measurement of executive function at age 5: Psychometric properties and relationship to academic achievement. Psychological Assessment, 24(1), 226-239.

Wilson, K. M., \& Swanson, H. L. (2001). Are mathematics disabilities due to a domain-general or a domainspecific working memory deficit? Journal of Learning Disabilities, 34(3), 237-248.

Yang, X., Chung, K. K. H., \& McBride, C. (2019). Longitudinal contributions of executive functioning and visual-spatial skills to mathematics learning in young Chinese children. Educational Psychology, 39(5), $678-704$

Zhang, X., \& Lin, D. (2015). Pathways to arithmetic: The role of visual-spatial and language skills in written arithmetic, arithmetic word problems, and nonsymbolic arithmetic. Contemporary Educational Psychology, $41,188-197$.

Zhang, X., Koponen, T., Räsänen, P., Aunola, K., Lerkkanen, M. K., \& Nurmi, J. E. (2014). Linguistic and spatial skills predict early arithmetic development via counting sequence knowledge. Child Development, 85(3), 1091-1107.

Publisher's note Springer Nature remains neutral with regard to jurisdictional claims in published maps and institutional affiliations.

Paola Bonifacci. Department of Psychology, University of Bologna, Viale Berti Pichat, 5, 40127 Bologna, Italy. E-mail: paola.bonifacci@unibo.it

\section{Current themes of research:}

Early literacy and numerical skills: cognitive and environmental predictors. Literacy development in bilingual language minority children and monolingual peers with and without Specific Learning Disorder. Emotional correlates of Specific Learning Disorders in children and their parents.

Most relevant publications in the field of Psychology of Education:

Bonifacci, P., Lombardo, G., Pedrinazzi, J., Terracina, F. \& Palladino, P. (2019, in press). Literacy skills in bilinguals and monolinguals with different SES. Reading and Writing Quarterly, DOI: 10.1080/ 10573569.2019.1635057

Bonifacci, P., Barbieri, M., Tomassini, M., \& Roch, M. (2018). In few words: Linguistic gap but adequate narrative structure in preschool bilingual children. Journal of Child Language, 45(1), 120-147.

Desideri, L., Ottaviani, C., Cecchetto C., Bonifacci, P. (2018). Mind wandering, together with test anxiety and self-efficacy, predict student's academic self-concept but not reading comprehension skills. British Journal of Educational Psychology. DOI:10.1111/bjep.12240

Bonifacci, P., Canducci, E., Gravagna, G. \& Palladino, P. (2017, in press). English as a foreign language in bilingual language-minority children, children with dyslexia and monolingual typical readers. Dyslexia, 23(2), 181-206. DOI: 10.1002/dys.1553 
Bonifacci, P., \& Tobia, V. (2017). The simple view of reading in bilingual language-minority children acquiring a highly transparent second language. Scientific Studies of Reading, 21(2), 109-119.

Bonifacci, P., Storti, M., Tobia, \& V., Suardi, A. (2016). Specific learning disabilities: A look inside children's and parents' psychological wellbeing and relationships. Journal of Learning Disabilities, 49(5) 532-545.

Bonifacci, P., Tobia, V., Bernabini, L., Marzocchi, G.M (2016). Early literacy and numeracy skills in bilingual minority children: Toward a relative independence of linguistic and numerical processing. Frontiers in Psychology, DOI:10.3389/fpsyg.2016.01020

Bonifacci, P., Tobia, V. (2016). Crossing barriers: Profiles of reading and comprehension skills in early and late bilinguals, poor comprehenders, reading impaired, and typically developing children. Learning and Individual Differences, 47, 17-26.

Bonifacci, P., Montuschi, M., Lami, L., Snowling, M.J. (2014). Parents of children with dyslexia: Cognitive, emotional and behavioural profile. Dyslexia, 20(2), 175-190.

Bonifacci, P., Giombini, L., Bellocchi, S., \& Contento, S. (2011). Speed of processing, anticipation, inhibition and working memory in bilinguals. Developmental Science, 14(2), 256-269.

Bonifacci, P., Snowling, M. J. (2008). Speed of processing and reading disability: A cross-linguistic investigation of dyslexia and borderline intellectual functioning. Cognition, 107, 999-1017.

Bonifacci, P., Desideri, L., Ottaviani, C. (2015). Familiarity of faces: Sense or feeling? Journal of Psychophysiology, 29(1), 20-25.

Bonifacci, P., Candria, L., Contento, S. (2008). Reading and writing: What is the relationship with anxiety and depression? Reading and Writing: An Interdisciplinary Journal, 21(6): 609-625.

Bonifacci, P. (2004). Children with low motor ability have lower visual-motor integration ability but unaffected perceptual skills. Human Movement Science, 23, 157-168.

Nicole Trambagioli. Department of Psychology, University of Bologna, Viale Berti Pichat, 5, 40127 Bologna, Italy. E-mail: nicole.trambagioli2@unibo.it

Current themes of research:

Early literacy and numerical skills: cognitive and environmental predictors. Diagnosis and intervention in Specific Learning Disorder.

Most relevant publications in the field of Psychology of Education:

Trambagioli N., Giuliano P. (2017). Prerequisiti della Scrittura. In: P. Bonifacci e V. Tobia. Apprendere nella scuola dell'infanzia. Lo sviluppo dei prerequisiti. Roma: Carocci Editore

Trambagioli N., Masotti G., Serra P., Bonifacci P. (2015). "Indicatori di Difficoltà di Apprendimento nella scuola dell'infanzia: protocolli di osservazione e potenziamento didattico nell'ambito del Progetto Logos del Comune di Bologna”. Dislessia, 12(3), 337-355.

Luca Bernabini. Department of Psychology, University of Bologna, Viale Berti Pichat, 5, 40127 Bologna, Italy. E-mail: luca.bernabini2@unibo.it

Current themes of research:

Early literacy and numerical skills: cognitive and environmental predictors. Intergenerational models of math skills.

Most relevant publications in the field of Psychology of Education:

Barbieri, M., Bernabini, L. (2018). Intervenire per potenziare le competenze linguistiche nella scuola dell'Infanzia. In: P. Bonifacci e V. Tobia. Apprendere nella scuola dell'infanzia. Lo sviluppo dei prerequisiti. Roma: Carocci Editore

Tobia, V., Bonifacci, P., Bernabini, L., Marzocchi, G.M. (2019). Teachers, not parents, are able to predict time processing skills in preschoolers. British Journal of Developmental Psychology, DOI:10.1111/bjdp.12294

Bonifacci, P., Tobia, V., Bernabini, L., Marzocchi, G.M (2016). Early literacy and numeracy skills in bilingual minority children: Toward a relative independence of linguistic and numerical processing. Frontiers in Psychology, DOI:10.3389/fpsyg.2016.01020

Valentina Tobia. Faculty of Psychology, University Vita-Salute San Raffaele, Via Olgettina 58, 20132 Milan, Italy. E-mail: tobia.valentina@unisr.it 
Current themes of research:

Prerequisites and cognitive profile in Specific Learning Disorders; school wellbeing; interaction between emotions and learning skills.

\section{Most relevant publications in the field of Psychology of Education:}

Tobia, V., Bonifacci, P., Bernabini, L., \& Marzocchi, G. M. (2019). Teachers, not parents, are able to predict time processing skills in preschoolers. British Journal of Developmental Psychology, 37(4), 519-534. https://oi. org/10.1111/bjdp.12294

Tobia, V., Greco, A., Steca, P., \& Marzocchi, G. M. (2019). Children's wellbeing at school: A multi-dimensional and multi-informant approach. Journal of Happiness Studies, 20(3), 841-861. doi: 10.1007/s10902-0189974-2

Tobia, V., \& Marzocchi, G. M. (2018). The strengths and difficulties questionnaire-parents for Italian schoolaged children: Psychometric properties and norms. Child Psychiatry \& Human Development, 49(1), 1-8. doi: 10.1007/s10578-017-0723-2

Tobia, V., Brigstocke S., Hulme, C., \& Snowling, M. J. (2018). Developmental changes in the cognitive and educational profiles of children and adolescents with 22q11.2 deletion syndrome. Journal of Applied Research in Intellectual Disabilities, 31(1), e177-e181. doi: 10.1111/jar.12344.

Tobia, V., Rinaldi, L., Marzocchi, G. M. (2018). Time processing impairments in preschoolers at risk of developing difficulties in mathematics. Developmental Science, 21(2), e12526. doi: 10.1111/desc.12526

Tobia, V., Riva, P., \& Caprin, C. (2017). Who are the children most vulnerable to social exclusion? The moderating role of self-esteem, popularity, and nonverbal intelligence on cognitive performance following social exclusion. Journal of Abnormal Child Psychology, 45(4), 789-801. doi: 10.1007/s10802-016-0191-3

Tobia, V., Ciancaleoni, M., \& Bonifacci, P. (2017). Theoretical models of comprehension skills tested through a comprehension assessment battery for children. Language Testing, 34(2), 223-239. doi: 10.1177/ 0265532215625705

Tobia, V., Fasola, A., Lupieri, A., \& Marzocchi, G. M. (2016). Numerical magnitude representation in children with mathematical difficulties with or without reading difficulties. Journal of Learning Disabilities, 49(2), 115-129.

Tobia, V., Bonifacci, P., \& Marzocchi, G. M. (2016). Concurrent and longitudinal predictors of calculation skills in preschoolers. European Journal of Psychology of Education, 31(2), 155-174.

Tobia, V., Bonifacci, P., Ottaviani, C., Borsato, T., \& Marzocchi, G. M. (2016). Reading under the skin: Physiological activation during reading in children with dyslexia and typical readers. Annals of Dyslexia, 66, 171-186.

Tobia, V., \& Bonifacci, P. (2015). The simple view of reading in a transparent orthography: The stronger role of oral comprehension. Reading and writing: An interdisciplinary journal, 28(7), 939-957.

Tobia, V., \& Marzocchi, G. M. (2014). Cognitive profiles of Italian children with developmental dyslexia. Reading Research Quarterly, 49(4), 437-452.

Tobia, V., \& Marzocchi, G.M. (2014). Predictors of reading fluency in Italian orthography: Evidence from a cross-sectional study of primary school students. Child neuropsychology, 20(4), 449-469.

Tobia, V., Gabriele, M.A., \& Marzocchi, G.M. (2013). The Italian version of the Strengths and Difficulties Questionnaire (SDQ) - Teacher: Psychometric properties. Journal of Psychoeducational Assessment, 31(5), 493-505.

Springer Nature remains neutral with regard to jurisdictional claims in published maps and institutional affiliations. 